\title{
Manufacture and performance of peanut skin cellulose nanocrystals
}

\author{
Anny Manrich* ${ }^{(\mathbb{D}}$, Maria Alice Martins ${ }^{\circledR}$, Luiz Henrique Capparelli Mattoso $₫$
}

Embrapa Instrumentação - Lab. Nacional de Nanotecnologia para o Agronegócio, R. XV de Novembro, 1452 - 3560-970

- São Carlos, SP - Brasil.

*Corresponding author <anny@daad-alumni.de>

Edited by: Thiago Libório Romanelli

Received February 23, 2021

Accepted August 11, 2021
ABSTRACT: Due to their remarkable characteristics, cellulose nanocrystals are strategic materials that has various industrial applications, and are capable of being produced from vegetable fibers derived from the discards of agricultural practices. Peanut (Arachis hypogaea L.) peel is a residue considered of low commercial value and high polluting potential that needs new applications in order to mitigate these problems. Thus, in this study the feasibility of extracting cellulose nanocrystals was investigated. Two chemical routes were followed for this extraction. In the first, the fibers were bleached before acid hydrolysis whereas mercerization was used in the second. The second route was more efficient, as it enabled the elimination of proteins and phenolic compounds, which could be confirmed through solid-state ${ }^{13} \mathrm{C}$ nuclear magnetic resonance (NMR) that revealed no signs of lignin residues. The cellulose nanocrystals composed of mainly type I cellulose presented a high degree of crystallinity index, $75 \%$, a thermal stability up to $200{ }^{\circ} \mathrm{C}$, considerable stability in suspension (zeta potential of $-48.1 \pm 2.1 \mathrm{mV}$ ), and an aspect ratio of 125 . They represent options that could add value to this residue, which would ease environmental problems.

Keywords: acid hydrolysis, agricultural residue, mercerization, waste

\section{Introduction}

About 45 million tons of peanuts (Arachis hypogaea L.) were produced in 2019 in the world (National Peanut Board, 2019). The skin or peel is an underutilized residue of the peanut processing industry. About 35 to $45 \mathrm{~g}$ of peanut peel $(\mathrm{PP})$ are generated per $\mathrm{kg}$ of shelled peanut kernel, reaching over 1.5 million tons yearly (Hathorn and Sanders, 2012; Pandey et al., 2018). Due to high levels of tannins, PP is not suitable for cattle feed, and is generally discarded leading to environmental contaminations (Zhao et al., 2012; Sobolev and Cole, 2003).

Development of a value-added product from waste PP could benefit both the peanut industry and the environment. Rich in polyphenolic compounds, lipids and proteins (Pandey et al., 2018; Zhao et al., 2012), PP can be used for production of active carbon (Saxena and Sarkar, 2012), antioxidants (Hathorn and Sanders, 2012), dyeing of textiles and as reinforcing filler in polymer composites, such as cassava starch-peanut skin based foams (Husen and Jawaid, 2020; Machado et al., 2019). Peanut skin contains approximately $18 \%$ fiber and $41 \%$ other carbohydrates (Machado et al., 2019).

Nanocellulose has unique properties such as improved mechanical properties, biodegradability, biocompatibility and high aspect ratio (Nechyporchuk et al., 2016; Yousefian, and Rodrigue, 2016). There are two main processes for obtaining nanocellulose (Nechyporchuk et al., 2016): (i) by acid treatment or chemical route, referred to as cellulose nanocrystals (CNC), and (ii) produced mainly by mechanical disintegration, called cellulose nanofibrils $(\mathrm{CNF})$. While $\mathrm{CNF}$ can be $20-50 \mathrm{~nm}$ in width and $500-2000 \mathrm{~nm}$ in length, CNCs can vary in diameter in the range of 5 to $50 \mathrm{~nm}$ and length in the range of 100 to $500 \mathrm{~nm}$ (Kargarzadeh et al., 2017).
The possibility of obtaining nanocellulose from PP could contribute to less residue discard. When the chemical path is applied, lignocellulosic material undergoes pretreatments which allow for partial separation of the cellulose such as mercerization (alkali treatment), and bleaching which disposes of the lignin and hemicellulose components. Sequentially, by controlled acid hydrolysis, amorphous regions of the cellulose are removed, and crystalline cellulose is isolated in the form of cellulose nanocrystals (Kalashnikova et al., 2012). In this study, two strategies were deployed to obtain CNC from PP. First, fibers were submitted to acid hydrolysis after simple bleaching. For the second essay, fibers suffered $\mathrm{NaOH}$ mercerization prior to bleaching and acid hydrolysis.

\section{Materials and Methods}

\section{Material}

Peanuts from the Valencia group were acquired from local markets (São Carlos, São Paulo State, Brazil, 22 $01^{\prime} 04^{\prime \prime} \mathrm{S}$ and $47^{\circ} 53^{\prime} 27^{\prime \prime} \mathrm{W}$, altitude $856 \mathrm{~m}$ ) and roasted at $200^{\circ} \mathrm{C}$ for $30 \mathrm{~min}$. Peanut peels (PP) were mechanically removed and milled to particle size of $0.5 \mathrm{~mm}$ or less. Next, this processed material was stored at room temperature $\left(25{ }^{\circ} \mathrm{C}\right)$. Sulfuric acid, $\mathrm{NaOH}, \mathrm{NaClO}_{2}, \mathrm{KBr}$, ethanol $99.5 \%$, hexane and acetic acid were of analytical grade. Cellulose dialysis membrane $12 \mathrm{KDa}$ was acquired from Sigma-Aldrich (St. Louis, USA).

\section{Experimental}

\section{Extractives elimination and determination}

Two subsequent procedures were carried out to eliminate and determine the extractive compounds from 
the peanut peel. First, $5.0 \mathrm{~g}$ of processed PP were boiled in $50 \mathrm{~mL}$ distilled water for $30 \mathrm{~min}$ for the extraction of hydrophilic compounds. The solid fraction was dried at $40{ }^{\circ} \mathrm{C}$ for $48 \mathrm{~h}$ and the liquid fraction lyophilized (Bansode et al., 2012). Next, the extraction of lipids was performed using hexane in a soxhlet extractor for continuous extraction using a conventional lab scale Soxhlet extractor with a routine of $8 \mathrm{~h}$ with ten cycles per $\mathrm{h}$ and dried once more at $40{ }^{\circ} \mathrm{C}$ for $48 \mathrm{~h}$.

\section{Chemical characterization}

The amount of ash from PP was determined as follows: an amount of $1 \mathrm{~g}$ of peanut skin was placed in a previously weighed crucible and then in a Muffle oven with the following schedule: (i) from $25^{\circ} \mathrm{C}$ up to $200{ }^{\circ} \mathrm{C}$ to $10^{\circ} \mathrm{C} \mathrm{min}{ }^{-1}$, maintained for $120 \mathrm{~min}$; (ii) temperature from $200{ }^{\circ} \mathrm{C}$ to $650{ }^{\circ} \mathrm{C}$ at $10{ }^{\circ} \mathrm{C} \mathrm{min}{ }^{-1}$, maintained for $180 \mathrm{~min}$; and (iii) cooling to room temperature.

The analysis was performed in triplicate, and the ash content was calculated as:

$$
\operatorname{ash}(\%)=\frac{\left(M_{f}-M_{i}\right)}{M_{i}}
$$

where $M_{f}=$ final mass of crucible containing ash and $M_{i}$ $=$ initial mass of crucible

Lignin and holocellulose (cellulose + hemicellulose) of PP were determined following the TAPPI standard T13m-54 and T19m-54, respectively (Nepomuceno et al., 2017). For the insoluble lignin, $1 \mathrm{~g}$ of PP was left under stirring in $15 \mathrm{~mL}$ of $72 \%$ sulfuric acid for $24 \mathrm{~h}$ and then under reflux for $4 \mathrm{~h}$. The suspension was then filtered using previously weighed glass filters and oven dried at $50{ }^{\circ} \mathrm{C}$ for $48 \mathrm{~h}$. The lignin content was identified by the difference between the dry filter weight containing lignin and the empty dry filter weight.

The holocellulose (cellulose + hemicellulose) was determined as follows: to a volume of $120 \mathrm{~mL}$ of water containing $1.0 \mathrm{~mL}$ of acetic acid and $2.5 \mathrm{~g}$ of sodium chlorite $3 \mathrm{~g}$ of PP was added and kept under stirring at $70{ }^{\circ} \mathrm{C}$. This procedure was repeated two more times and the volume was cooled in an ice bath, filtered through a sintered glass funnel and washed until reaching neutral $\mathrm{pH}$. The holocellulose funnel was oven dried at $100{ }^{\circ} \mathrm{C}$ for $24 \mathrm{~h}$ and weighed. To determine the amount of cellulose, $1 \mathrm{~g}$ of the dry holocellulose was ground with a pestle in a mortar with $15 \mathrm{~mL}$ of $17.5 \% \mathrm{NaOH}$ solution $(\mathrm{w} / \mathrm{v})$ for 8 min. A further $10 \mathrm{~mL}$ of the solution was added and the mixture was left to stand for $20 \mathrm{~min}$. Forty $\mathrm{mL}$ of distilled water was then added to the mixture and filtered through a sintered funnel. The material retained was washed with distilled water to neutral $\mathrm{pH}$ and oven dried at $100{ }^{\circ} \mathrm{C}$ for $24 \mathrm{~h}$ and weighed.

\section{Mercerization and bleaching}

Pretreatments were carried out by two routes to promote chemical extraction of CNC from the processed extractive-free peanut peel. In the first route, the processed extractive-free PP was bleached without prior mercerization followed by acid hydrolysis. A second route was then taken, whereby processed extractivefree PP was submitted first to mercerization and then to bleaching. The mercerization, $5.0 \mathrm{~g}$ of processed extractive-free PP was kept under strong mechanical stirring in $100 \mathrm{~mL}$ of $5 \%\left(\mathrm{~m} \mathrm{v}^{-1}\right) \mathrm{NaOH}$ at $60{ }^{\circ} \mathrm{C}$ for $120 \mathrm{~min}$. Next, the material was washed till it reached neutral $\mathrm{pH}$ and dried at $40^{\circ} \mathrm{C}$ for $48 \mathrm{~h}$. For the bleaching, $100 \mathrm{~mL}$ of solution containing $2.7 \mathrm{~g}$ of $\mathrm{NaOH}$ and $7.5 \mathrm{~mL}$ of acetic acid were prepared, heated to $80{ }^{\circ} \mathrm{C}$ and kept under strong mechanical stirring. To this solution, 2.0 $\mathrm{g}$ of dried mercerized peanut peel and $1.7 \mathrm{~g}$ of $\mathrm{NaClO}_{2}$ were added. The reaction was complete after $120 \mathrm{~min}$. Fibers were washed till they became neutral and dried at $40{ }^{\circ} \mathrm{C}$ for $48 \mathrm{~h}$. Both route samples were submitted to acid hydrolysis for cellulose nanocrystal extraction.

\section{Extraction of the cellulose nanocrystals (CNC) by acid hydrolysis}

The procedure to extract CNC was carried out according to Flauzino-Neto et al. (2013). The CNC was extracted from $1 \mathrm{~g}$ bleached fiber and from mercerized-bleached fiber using $20 \mathrm{~mL}$ of 60 wt $\%$ sulfuric acid at $45{ }^{\circ} \mathrm{C}$ for $30 \mathrm{~min}$ under strong stirring. Reaction halts by the addition of $100 \mathrm{~mL}$ of ice water due to both decreases in temperature and dilution of the solution. After a period of 120 min when decantation of the material was expected, the suspension was centrifuged at 10,000 rpm for $20 \mathrm{~min}$ and part of the volume was withdrawn. Concentrated suspension was then introduced into cellulose acetate membranes and dialyzed for five days. After this, the suspension containing CNC was dispersed using a sonifier tip (Tapped Step Horn 1/2" Tip Diameter) operating at $50 \%$ amplitude for $3 \mathrm{~min}$ in an ice water bath to avoid sample heating. With the dispersion, phase separation follows between cellulose nano and microfibers. Only CNC are stable in the suspension while microfibers sediment visibly. These volumes were separated using a micropipette, measured and dried by lyophilization. CNC samples were quantified and characterized. Due to different pretreatments, two distinct samples were identified: cellulose nanocrystals non-mercerized (CNCNM) and cellulose nanocrystals pre-mercerized (CNCPM).

Both CNC samples were characterized by nitrogen (protein) content, zeta potential, thermogravimetric analysis (TG/DTG), infrared spectroscopy (FTIR), X-Ray diffractometry (XDR) and scanning electron microscopy (SEM). The yield of the CNC extractions was calculated as:

yield $C N C(\%)=\frac{M_{C N C}}{M_{P P}} \times 100 \%$,

where $M_{C N C}$ is the final mass of $C N C$ extracted, and $M_{P P}$ the initial mass of PP used for the extraction. 


\section{Nitrogen and Protein Content}

Nitrogen content was determined using elemental analysis (CHN) equipment with data management software, operated at $925^{\circ} \mathrm{C}$ and $640{ }^{\circ} \mathrm{C}$ in combustion furnaces and reduction, respectively, in an argon atmosphere. A $5 \mathrm{mg}$ sample was weighed and analyzed for the composition of $\mathrm{C}, \mathrm{N}$ and $\mathrm{H}$. The percentage of protein present in the material was calculated by multiplying the nitrogen percentage by 6.25 (Hames et al., 2008).

\section{Zeta Potential}

Zeta potential of CNC was measured by the dynamic light scattering (DLS) technique in a DLS instrument. Suspensions (0.005 wt $\%$ in pure water, $\mathrm{pH}=6.5$ ) were previously dispersed using a sonifier tip (Tapped Step Horn 1/2" Tip Diameter) operating at $50 \%$ amplitude for $3 \mathrm{~min}$ in an ice/water bath to avoid heating.

\section{Thermogravimetric analysis}

Thermal stability (TG/DTG) of the CNC was evaluated under the following test conditions: heating rate of $10{ }^{\circ} \mathrm{C} \mathrm{m^{-1 }}$ in oxidative atmosphere (synthetic air),

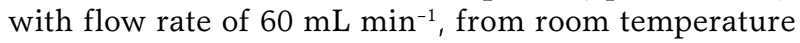
to $600{ }^{\circ} \mathrm{C}$. Approximately $10 \mathrm{mg}$ of each sample was used.

\section{Analysis by infrared spectroscopy}

Infrared spectroscopy (FTIR) was performed using a spectrophotometer with a wavelength of 400-4,000 $\mathrm{cm}^{-1}$. The samples were pressed into $\mathrm{KBr}$ pellets $(1 \mathrm{mg}$ peel per $100 \mathrm{mg} \mathrm{KBr}$ ). A plain $\mathrm{KBr}$ pellet was used as a blank.

\section{Analysis by X-Ray diffraction}

X-ray diffraction (XDR) analysis was carried out in an $\mathrm{X}$-ray diffractometer, operating at $30 \mathrm{kV}$ and $30 \mathrm{~mA}$ with $\mathrm{CuKa}$ radiation of $0.154 \mathrm{~nm}$, at $25{ }^{\circ} \mathrm{C}$ and $2 \theta$ angles between 5 and $40^{\circ}\left(0.5^{\circ} \mathrm{min}^{-1}\right)$. The crystallinity index (CI) was calculated according to Park et al. (2010). Crystalline peaks referred to cellulose and the broad peak assigned to hemicellulose were identified in the diffractograms, and a peak fitting tool, Multiple Peak Fit, from the OriginLab software (version 9.0) was used to fit Gaussian functions for each peak. The CI was calculated as:

$C I(\%)=\left[1-\left(\frac{A_{a m}}{A_{t}}\right)\right] \times 100$,

where $A_{a m}=$ peak related to the amorphous phase (hemicellulose and amorphous cellulose) and $A_{t}$ $=$ total area (sum of all peaks identified in the diffractogram).

\section{Characterization through solid-state ${ }^{13} \mathrm{C}$ nuclear magnetic resonance $\left({ }^{13} \mathrm{C} \mathrm{NMR}\right)$}

Characterization using ${ }^{13} \mathrm{C}$ NMR was used to investigate the purity of the isolated cellulose in the CNCPM, since it can provide supplementary information on the molecular structure (Kouadri and Satha, 2018). ${ }^{13} \mathrm{C}$ NMR experiments were performed using a 400 $\mathrm{MHz}$ spectrometer. All spectra were recorded with a combination of cross-polarization, high-power proton decoupling, and magic angle spinning. ${ }^{13} \mathrm{C}$ NMR spectra were acquired at a spin rate of $10 \mathrm{kHz}$, a relaxation delay of $5 \mathrm{~s}$, an acquisition time of 40 milliseconds, a contact time of 1 millisecond, and a number of 1024 scans.

\section{Image analysis}

Microscopy analyses were carried out on a Scanning Electron Microscope equipped Scanning Electron with a field emission source (FEG - Field Emission Gun). The operation parameters used were: secondary electrons mode, accelerating voltage of $\max .4 .0 \mathrm{kV}$, beam current of $10.0 \mu \mathrm{A}$, work distance of $3.00 \mathrm{~mm}$, and probe current (spot size) of 7.0. Sizes for the diameter of the nanofibers were obtained using the ImageJ. image processing program. Approximately 100 single measurements were taken for each CNC sample.

\section{Statistical analysis}

One-way analysis of variance (ANOVA) was applied to the data. Mean values were compared using Tukey's test $(p<0.05)$. All statistical calculi were made in the OriginLab software (version 9.0).

\section{Results}

\section{Chemical composition and yield}

The chemical composition of the peanut peels used had been previously determined by our research group (data not shown), and the results were: $2.0 \pm 0.3 \%$ ashes, $8.2 \pm 0.8 \%$ lipids, $17.8 \pm 1.4 \%$ protein, $23.7 \pm$ $2.0 \%$ cellulose, $20.9 \pm 2.0 \%$ hemicellulose, $5.0 \pm 0.6 \%$ aqueous extractives and $20.2 \pm 1.0 \%$ lignin. Protein contents for CNCNM and CNCPM obtained from peanut peels were $21.7 \pm 1.4$ and $1.87 \pm 0.2 \mathrm{wt} \%$, respectively. The nanocrystals obtained without the previous procedure of mercerization, route 1 , maintained the coloration of peanut peel (Figure 1), possibly due to the presence of phenolic compounds, for the main part procyanidins (Constanza et al., 2012), since these compounds are strongly bound to the proteins (Xu et al., 2012) and may not have been totally eliminated from the material. The value of protein for CNCNM was even higher than that from the peanut peel itself, showing that the extraction of CNC after simply bleaching and acid hydrolysis concentrated the proteins. On the other 


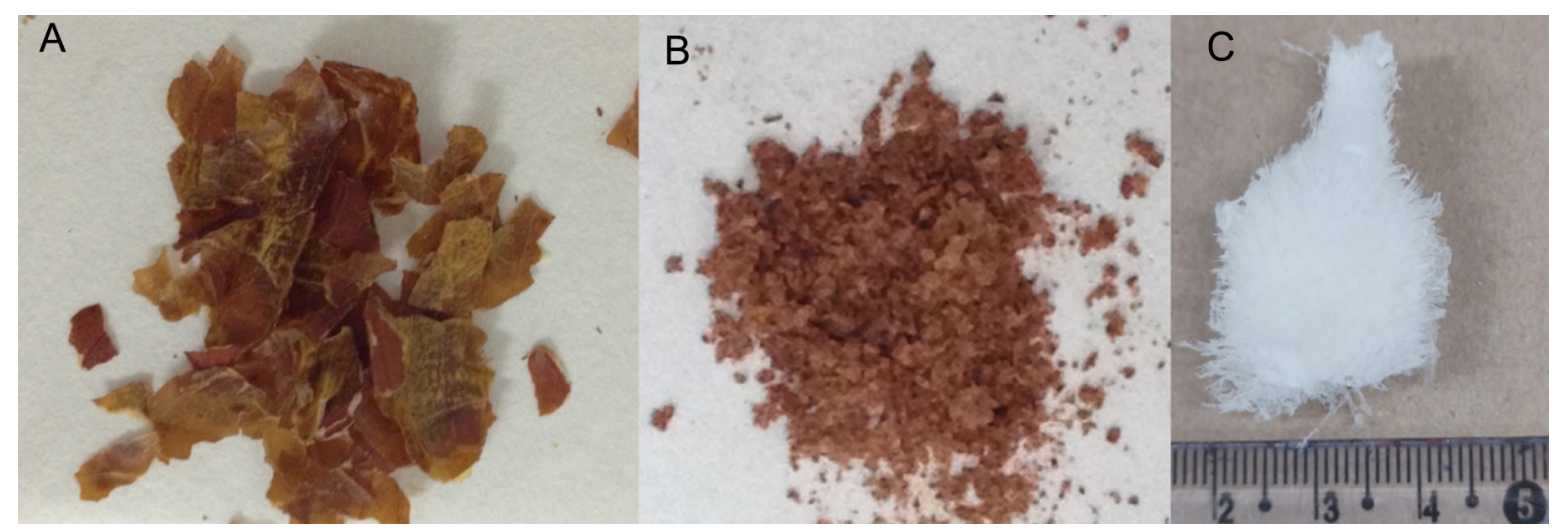

Figure 1 - Images of visual aspect of: $A=$ roasted peanut peel, $B=$ lyophilized cellulose nanocrystals non-mercerized (CNCNM), and $\mathrm{C}=$ lyophilized cellulose nanocrystals pre-mercerized (CNCPM).

hand, for CNCPM most of the lignin and hemicellulose contents were removed, which was evidenced by the FTIR and XDR results that will be shown below. The values measured for zeta potential for CNCNM and CNCPM were $-31.0 \pm 4.1$ and $-48.1 \pm 2.1$, respectively.

Pre-mercerized cellulose nanocrystals (CNCPM) had a lower protein content than peanut peel and CNCNM, and lower mass yield than CNCNM. The zeta potential, however, has increased more than $50 \%$ higher than CNCNM. The typical staining was lost, demonstrating that phenolic compounds were eliminated. The mercerization procedure removed both protein and phenolic compounds, resulting in a more stable material in suspension. The CNCPM route had a yield (obtained mass / peanut peel mass) of $3.25 \pm 0.02$ wt $\%$ and a CNCNM yield of $5.28 \pm$ 0.39 wt \%, probably due to different compositions of the samples in the two routes used.

\section{Protein Content and Zeta Potential}

The dynamic light scattering technique provides satisfactory information on the size of the nanoparticles suspended in a medium and their stability through storage. For molecules in the nano-scale, a high value for zeta potential indicates that dispersion will resist aggregation. Briefly, zeta potential values higher than $\pm 30 \mathrm{mV}$ (as module) indicate stability (Silva et al., 2012; Tonoli et al., 2012). Value obtained for the CNCPM was $-48.1 \pm 2.1 \mathrm{mV}$, which demonstrates the high stability of the suspension, comparable to the values found for raw cotton linter nanocellulose, $-45.3 \pm 1.4 \mathrm{mV}$ (Morais et al., 2013) and superior to which Tonoli et al. (2012) and Teixeira et al. (2010) reported for eucalyptus and cotton CNF, of $-34.2 \pm 3.2$ and $-31 \pm 4.1$, respectively.

Negative values are due to the acid hydrolysis of the cellulose, which introduces negative charges to the CNC in water by substituting a number of hydroxyl groups with sulfate ester groups (Iwamoto et al., 2014). The zeta potential measured for the CNCNM was -31.0 $\pm 4 \mathrm{mV}$, which is still considered a stable suspension, although not as stable as the former one, which presents a higher charge level, that is, a higher degree of sulfate groups could be introduced. Thus, cellulose was easily accessed due to the elimination of protein (Iwamoto et al., 2014; Niu et al., 2017).

\section{Thermogravimetric analysis}

For peanut peels there are four main steps of degradation, and for both CNC samples there are three main steps Figure $2(\mathrm{~A}-\mathrm{C})$. In all cases, the first one corresponds to elimination of volatiles and bounded water at temperatures below $100{ }^{\circ} \mathrm{C}$. The second step starting at $200{ }^{\circ} \mathrm{C}$ corresponds, in the case of the $\mathrm{PP}$, to the decomposition of hemicelluloses, with a maximum at $273{ }^{\circ} \mathrm{C}$ followed by the degradation of the glycosidic linkages in cellulose, with a maximum at $315{ }^{\circ} \mathrm{C}$ (Nabinejad et al., 2015). For the CNC samples, a slight shoulder on the TG curves at $250{ }^{\circ} \mathrm{C}$ demonstrates the presence of hemicelluloses, but in a reduced amount. The cellulose decomposition peak occurs with a maximum at $295^{\circ} \mathrm{C}$ and $350{ }^{\circ} \mathrm{C}$ for $\mathrm{CNCPM}$ and CNCNM, respectively.

A greater quantity of sulphate groups in the CNCPM due to more successful treatment with sulphuric acid was found to be responsible for the reduced thermostability of the nanocrystals (Bano and Negi, 2017). The intense peaks at $450{ }^{\circ} \mathrm{C}$ and $495{ }^{\circ} \mathrm{C}$ for CNCPM and CNCNM correspond to the lignin degradation added to residual protein constituents. The high quantity of protein in the CNCNM fibers shifts the peak to a higher temperature (Nabinejad et al., 2015). At temperatures above $500{ }^{\circ} \mathrm{C}$ oxidative combustion of degraded compounds and the decomposition of the residual lignin occurs (Tonoli et al., 2012).

\section{Characterization by FTIR Spectroscopy}

The differences between the FTIR spectra of peanut peel and both samples extracted. CNC are noticeable, indicating their different structures and chemical compositions (Figure 3). Table 1 presents the main absorption peaks and 

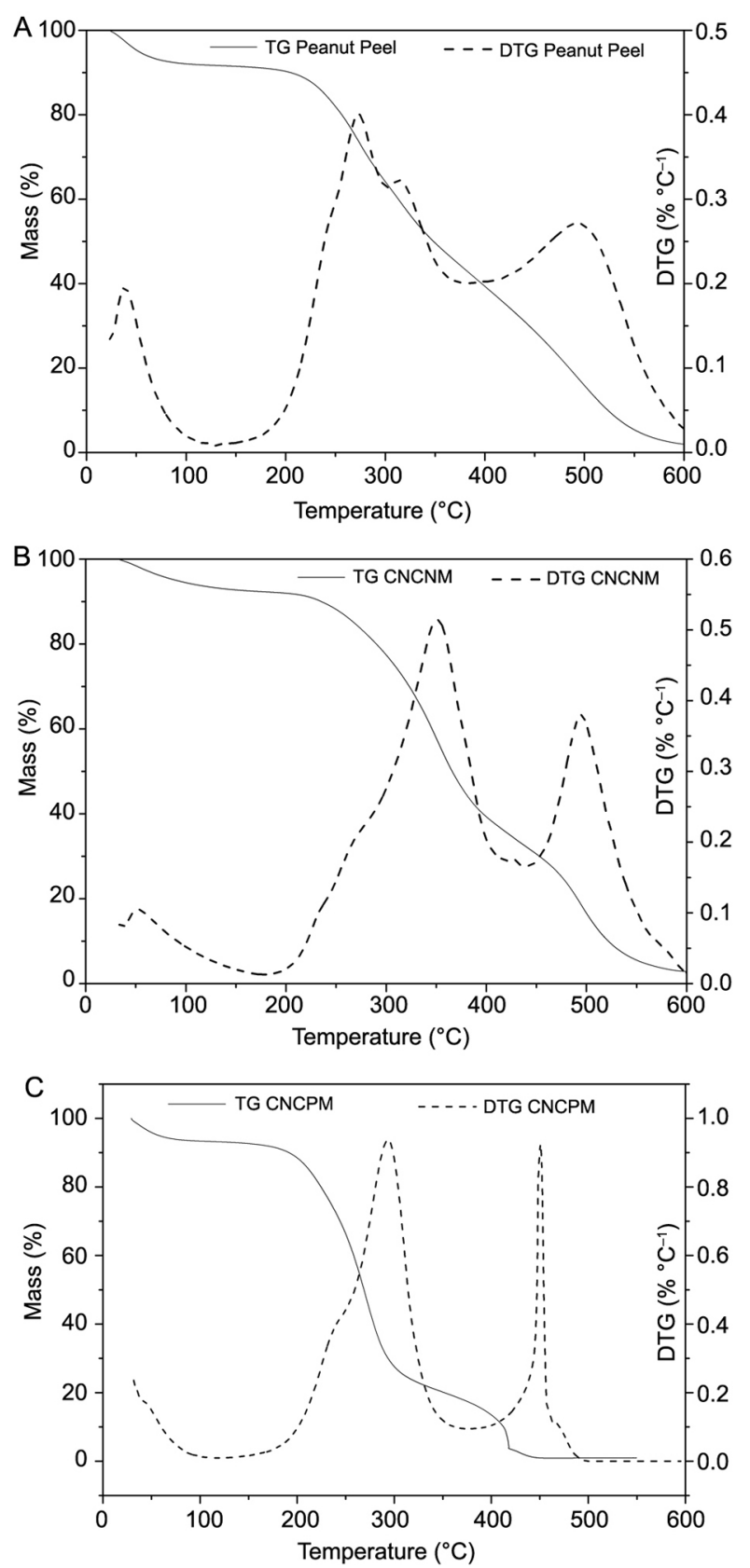

Figure $2-A=$ Curves of $T G$ and DTG of the peanut peel; $B=$ cellulose nanocrystals non-mercerized - CNCNM, and $\mathrm{C}=$ cellulose nanocrystals pre-mercerized (CNCPM), in oxidative atmosphere (synthetic air).

their respective chemical structure for the peanut peel and both CNC samples. Many peaks related to the cellulose structure are perceptible in the spectra of both samples of $\mathrm{CNC}$, such as at $2,020 / 2,922 \mathrm{~cm}^{-1}\left(\mathrm{CH}_{2}\right.$, asymmetric stretching), at $1,373 / 1,321$ and $1,280 / 1,240 \mathrm{~cm}^{-1} \mid \mathrm{CH}$ bending); at $1,161 / 1,053 \mathrm{~cm}^{-1}$ (C-O-C from pyranose), 1,100 and $894 \mathrm{~cm}^{-1}$ C-O-C from $\beta-1,4$ gycosidic linkages and $1,033 / 1,000 \mathrm{~cm}^{-1}$ assigned as $\mathrm{C}-\mathrm{OH}$ vibrations of

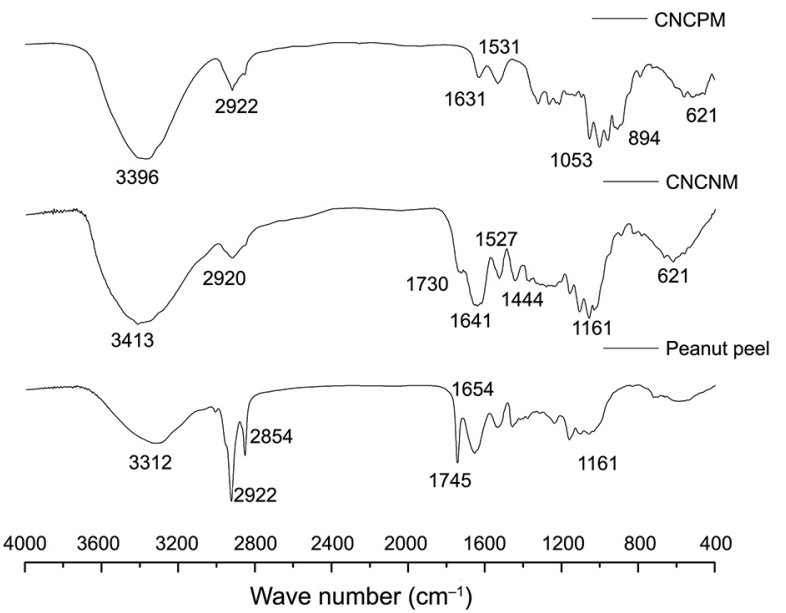

Figure 3 - Furrier Transformed Infrared spectra of peanut peel, cellulose nanocrystals non-mercerized (CNCNM) and, cellulose nanocrystals pre-mercerized (CNCPM).

cellulose (Mariano et al., 2018; Fang et al., 2014; Sofla et al., 2016). Band shiftings are due probably to a number of modifications in the CNCPM structure during chemical treatment with $\mathrm{NaOH}$ (Mariano et al., 2018).

The weakened peak in the CNCNM at $1,730 \mathrm{~cm}^{-1}$ related to hemicelluloses and lignin demonstrates that these structures were successfully reduced in relation to PP (Fang et al., 2014) and the absence of this peak in the CNCPM spectrum shows that they were totally removed. The peak at $1,631 \mathrm{~cm}^{-1}$ for CNCPM is related to $\mathrm{O}-\mathrm{H}$ bending of the absorbed water in CNC (Mariano et al., 2018). According to Sofla et al. (2016), water is confined within the cellulosic structure when hemicelluloses and lignin are removed resulting in gains in $\mathrm{CNC}$ and water absorption that are high due to increases in surface area. This peak is present in the spectrum of CNCNM at 1,641 $\mathrm{cm}^{-1}$ but it can also be attributed to the amide I, Figure 3 and Table 1, (Smidt and Schwanninger, 2005).

Additional adsorption peaks between 1,000 and $1,100 \mathrm{~cm}^{-1}$ for both CNC spectra indicate the increase in cellulose content in relation to PP. The broad band at $3,312 \mathrm{~cm}^{-1}$ (in PP) is related to the $-\mathrm{OH}$ stretching of the hydrogen bonds, and its shifting in CNCPM and CNCNM indicates a weakening of the intensity of intermolecular hydrogen bond, due to chemical processing (Fang et al., 2014).

Peanut peel contains lipids whose bands are found in 2,922 and $2,854 \mathrm{~cm}^{-1}\left(-\mathrm{CH},-\mathrm{CH}_{2}-\mathrm{CH}_{3}\right.$, alkane saturation); $3,010,1,654$ and $1,458 \mathrm{~cm}^{-1}(\mathrm{H}-\mathrm{C}=\mathrm{C}-\mathrm{H}$, unsaturated fatty acid), and in $1,745 \mathrm{~cm}^{-1} \mathrm{C}=\mathrm{O}$ stretch, ester groups) (Barcelo et al., 2015; Benitez et al., 2004).

Furthermore, bands from aromatic $\mathrm{C}-\mathrm{O}-\mathrm{H}$ groups are visible in 1,240 and $719 \mathrm{~cm}^{-1}$, evidencing phenolic compounds (Sofla et al., 2016). Absorptions of protein structures containing $\mathrm{C}-\mathrm{N}$ and $\mathrm{N}-\mathrm{H}$ are evident between 1,400 and $1,550 \mathrm{~cm}^{-1}$ for both peanut peel and CNC samples (Win et al., 2011). 
Table 1 - Furrier Transformed Infrared Spectroscopy (FTIR) main peaks with corresponding chemical structure for peanut peel, cellulose nanocrystals non-mercerized (CNCNM) and, cellulose nanocrystals pre-mercerized (CNCPM).

\begin{tabular}{|c|c|c|c|c|}
\hline Wave number & Chemical group/structure & \multicolumn{2}{|c|}{ Wave number } & Chemical group/structure \\
\hline $\mathrm{cm}^{-1}$ & & \multicolumn{2}{|c|}{$\mathrm{cm}^{-1} \longrightarrow$} & \\
\hline Peanut peel & & CNCNM & CNCPM & \\
\hline 3,312 & $-\mathrm{H}$ stretching of $\mathrm{OH}$, cellulose & 3,413 & 3,396 & $-\mathrm{H}$ stretching of $\mathrm{OH}$ in cellulose \\
\hline $2,922 / 2,854$ & $-\mathrm{CH},-\mathrm{CH}_{2}-\mathrm{CH}_{3}$, alkane saturation, fatty acids & 2,920 & 2,922 & $-\mathrm{CH}_{2}$, asymmetric stretching of methylene group, cellulose \\
\hline 1,745 & $\mathrm{C}=0$ stretch, ester groups, lipids and lignin & 1,730 & - & Carboxylic acid, Hemicelluloses \\
\hline 1,654 & $\mathrm{C}=\mathrm{C}$ alkenyl stretch, unsaturated fatty acids & 1,641 & 1,631 & $\begin{array}{l}\text { Amide I vibrations (B-sheet) } \\
-\mathrm{OH} \text { bending of absorbed water }\end{array}$ \\
\hline 1,535 & Amide II group of protein structure & $1,527 / 1,444$ & 1,531 & $\begin{array}{l}-\mathrm{C}-\mathrm{H} \text { and } \mathrm{C}-\mathrm{N} \text {, carbohydrates and proteins } \\
\mathrm{C}-\mathrm{O} \text { angular vibrations, carbohydrates }\end{array}$ \\
\hline 1,458 & Bending - C-H group of fatty acid & $1,373 / 1,280$ & $1,321 / 1,240$ & $\begin{array}{l}\text { C-N stretching of amides } \\
\text { Twist vibration } \mathrm{C}-\mathrm{H}_{2} \text {, cellulose }\end{array}$ \\
\hline 1,161 & asymmetric stretching of the $\mathrm{C}-\mathrm{O}-\mathrm{C}$ bond, cellulose & 1,161 & 1,053 & asymmetric stretching of the $\mathrm{C}-0$ pyranose, cellulose \\
\hline 1,240 & Aromatic ethers, aryl - 0 stretching & $1,100 / 894$ & 894 & C-O-C stretching at B 1,4 glycosidic linkages. \\
\hline \multirow[t]{2}{*}{719} & Aromatic $\mathrm{C}-\mathrm{H}$ out of plane bend & 1,033 & 1,000 & $\mathrm{C}-\mathrm{O}$ bonds in cellulose \\
\hline & & 621 & 563 & $-\mathrm{C}-\mathrm{H}$ and $-\mathrm{OH}$ out of plane, cellulose \\
\hline
\end{tabular}

\section{Characterization by XDR}

Thecrystallinityindexwascalculatedbythedeconvolution method. According to the literature, the CI calculated by deconvolution is more accurate, since the exact amount of the crystalline fraction in the lignocellulosic materials are more related to the peak area rather than its height, as the height calculation method determines the relative crystallinity only (Karimi and Taherzadeh, 2015; Park et al., 2010). The cellulose nanocrystals extracted after only bleaching and acid hydrolysis, i.e., without the mercerization step, presented a higher halo at $2 \theta$ of $18.5^{\circ}$ corresponding to the amorphous structures of the material, with a reduction in CI from $53 \%$ for the PP to $24 \%$ for the CNCNM. This can be explained by the partial elimination of hemicellulose and lignin, which leads to the relative higher concentration of protein in the CNCNM as compared to the PP.

In the diffractogram of CNCNM, a sharp peak at $2 \theta$ of $12.2^{\circ}$ characterizes type II cellulose. According to Klemm et al. (2005) the parallel chain arrangement of type 1 cellulose may undergo a change in the orientation to antiparallel arrangements becoming type II cellulose II through treatment with aqueous sodium hydroxide. However, this peak is not present in the diffractogram for CNCPM, although it was twice submitted to aqueous treatments with $\mathrm{NaOH}$. In this case, the hemicelluloses and other non-cellulosic structures were eliminated from the biomass without damaging the cellulose nanofibers, indicating that this is the best route.

The crystallinity index shifted from $53 \%$ for the PP to $75 \%$ for the CNCPM due to the different arrangements of the glucose chains in cellulose molecules after acid extraction of the peanut peel and removal of the amorphous phase, confirmed by FTIR analysis (Wang et al., 2007). The main peaks of both $\mathrm{PP}$ and $\mathrm{CNCPM}$ are found in $2 \theta$ of around $15.5^{\circ}, 22.5^{\circ}$ and $34.5^{\circ}$, which are characteristic of type I cellulose polymorph (Klemm et al., 2005; Gupta et al., 2013).
Figure 4 shows the XRD patterns of peanut peel (A), CNCNM (B) and CNCPM (C) with their respective main peaks and fitted curves.

Cellulose nanocrystals obtained from other agricultural by-products via chemical extraction yield similar crystallinity indexes. Flauzino-Neto et al. (2013) extracted CNC from soybean hulls by using $64 \% \mathrm{H}_{2} \mathrm{SO}_{4}$ for $30 \mathrm{~min}$ at $40{ }^{\circ} \mathrm{C}$, which resulted in rod-shaped $\mathrm{CNC}$ of $73.5 \%$ crystallinity; $64 \% \mathrm{H}_{2} \mathrm{SO}_{4}$ was also used to extract CNC from sugarcane bagasse, although for 60 min at $45{ }^{\circ} \mathrm{C}$, resulting in a needle-like material of $73 \%$ crystallinity (Sofla et al., 2016). Certain crop residues

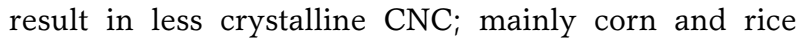
husks, with 70.7 and $59.0 \%$, respectively (Song et al., 2019). The final crystallinity of nanocellulose depends on different origin and process conditions, and the various pretreatments chosen for cellulose isolation (Husen and Jawaid, 2020).

\section{Characterization through ${ }^{13} \mathrm{C}$ NMR}

Cellulose nanocrystals pre-mercerized were analyzed through solid state ${ }^{13} \mathrm{C}$ NMR and the resulting spectrum (Figure 5), providing evidence that the isolated CNC are composed mainly of cellulose. Peaks related to cellulose are at 84 and 89 ppm of C-4, of crystalline and amorphous cellulose respectively (Modica et al., 2020). The signal at $105 \mathrm{ppm}$ is assigned to $\mathrm{C} 1$, the peak at $63 \mathrm{ppm}$ is due to $\mathrm{C} 6$ of the crystalline cellulose and the peaks at 105 and at $72-75$ ppm were attributed to the total cellulose (Kouadri and Satha, 2018). CNC were free from lignin; thus, no signals assigned to aromatic groups were detected, mainly at 110 and $150 \mathrm{ppm}$; and also free from hemicellulose signals, which usually appear at 22, 56 and 174 ppm (Cipriano et al., 2020). This validates previous FTIR and DRX characterizations, which demonstrate that the chemical extraction sequence chosen for the production of $\mathrm{CNC}$ was correct. 

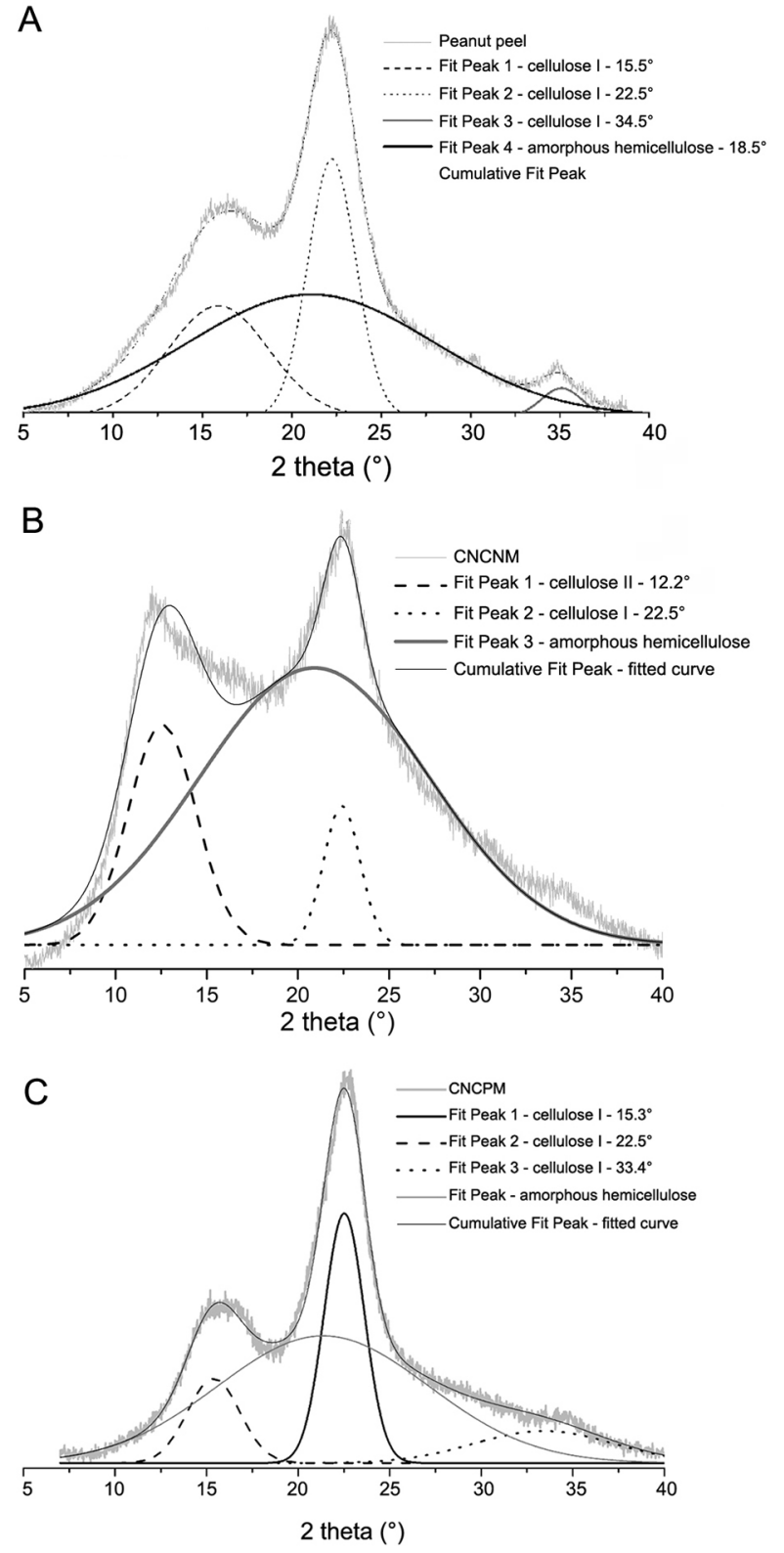

Figure $4-A=X$-Ray Diffraction spectra of peanut peel; $B=$ cellulose nanocrystals non-mercerized (CNCNM), and $C=$ cellulose nanocrystals pre-mercerized (CNCPM).

\section{Image analysis by FEG-SEM}

Cellulose nanofibers extracted from peanut peel are needle-like structures with a high aspect ratio (namely, length/diameter). Dimensions are approximately 4 $\mathrm{nm}$ of diameter and $500 \mathrm{~nm}$ of length, and an aspect

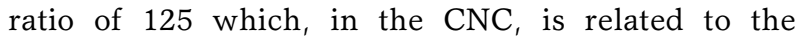
original cellulose fibers and the process chosen for obtaining them. Generally, longer hydrolysis reactions depolymerize cellulose chains and reduce both the

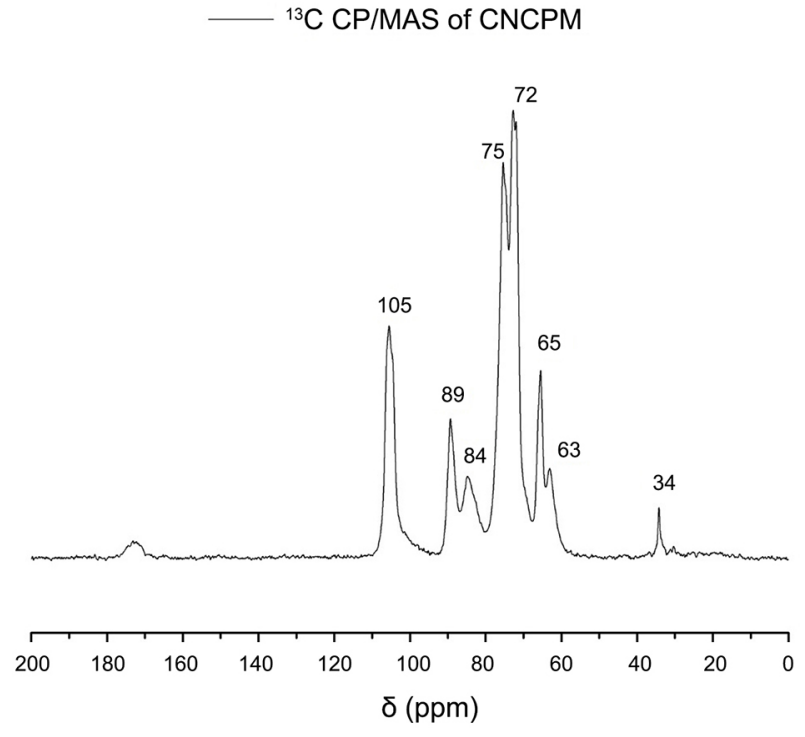

Figure 5 - Solid-state $13 \mathrm{C}$ nuclear magnetic resonance spectrum of cellulose nanocrystals pre-mercerized (CNCPM).

nanofiber lengths and aspect ratios. When used as material fillers in nanomaterials, it is positive to have high aspect ratios, since a high aspect ratio can ensure the percolated network is held by strong hydrogen bonding interactions that results in mechanical improvements, increasing stiffness and thermal stability at lower nanofiber loadings (Tonoli et al., 2012; Peng et al., 2011).

Images of CNC from peanut peel obtained by FEG-SEM are shown in Figure 5. Where the peanut peel had not been previously mercerized, CNCNM, (Figure 6A and 6B), the fibers produced, although nanometric, were not separated as individual fibers. Thus, the aspect ratio could not be measured. The fibrous material remained as a large cellulosic matrix that cannot be dismembered. This was probably because compounds such as the remaining hemicellulose, protein and lignin were still attached to the cellulose fibers, which hindered an efficient performance of the sulfuric acid by dismembering and fragmenting cellulose fibrils into individual and short fibers (Abraham et al., 2013).

The mercerization is traditionally used to extract impurities from cellulose pulp and has a beneficial effect on disintegrating the fiber, exposing them to hydrolysis, in which short fibers are produced (Nechyporchuk et al., 2016). Images of CNCPM are shown in Figures 6C and 6D and differ from CNCNM. They are, for the most part, short needle-like fibers that can be measured as individual fibers. This shows that the mercerization step was critical to the achieving of nanometric individual fibers, as it removed noncellulosic components of the fibers, permitting the action of acid hydrolysis. 


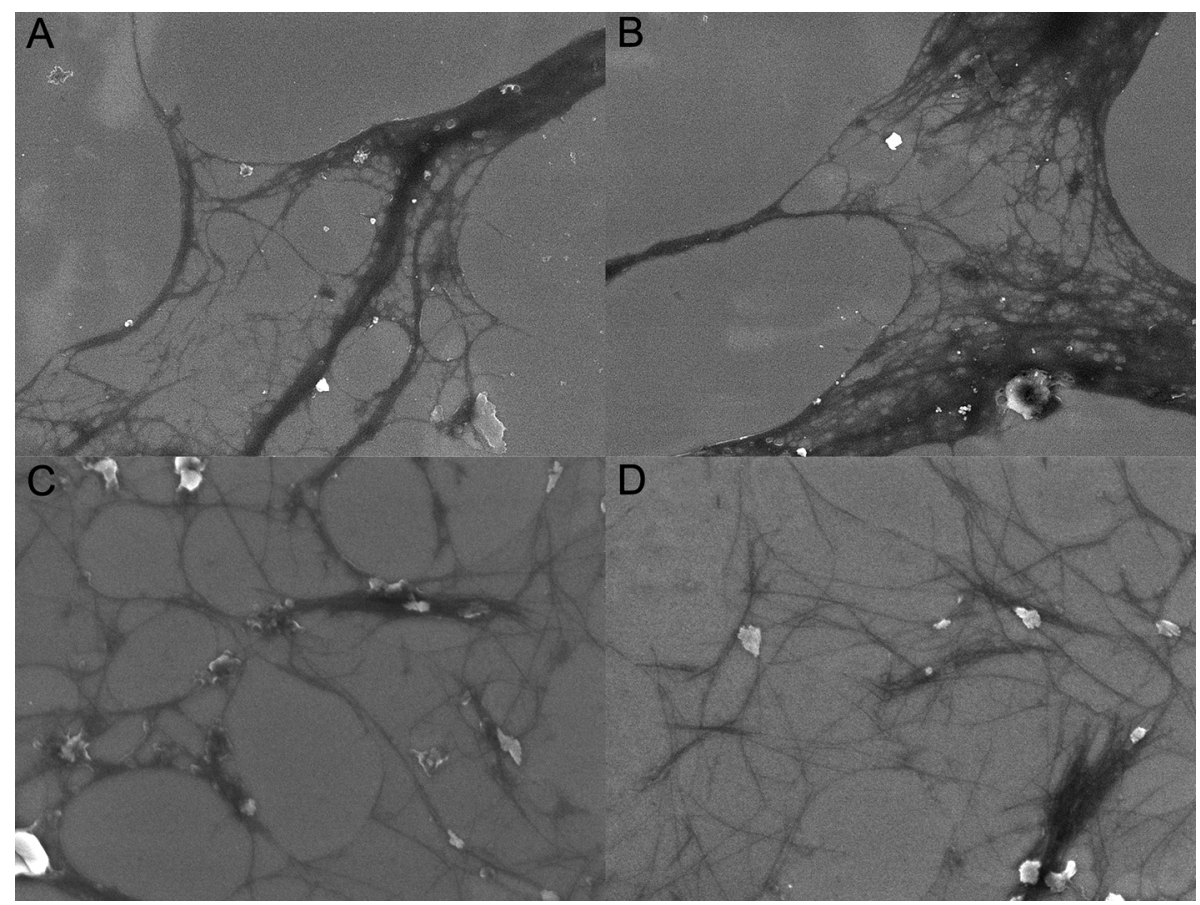

Figure 6 - A = Scanning electron microscopy images of cellulose nanofiber extracted from peanut peel non-mercerized - CNCNM, (increase of 20,000 times) and $B=$ (increase of 20,000 times) and SEM images of cellulose nanocrystals extracted from peanut peel pre-mercerized (CNCPM), $C$ and $D=$ (increase of 50,000 times).

\section{Conclusions}

When no mercerization was performed preceding bleaching and acid hydrolysis, $5.28 \pm 0.39$ wt \% of yield of CNC rich in protein and phenolic compounds were produced, with a CI of only $24 \%$. Mercerization using $\mathrm{NaOH}$ followed by bleaching and acid hydrolysis of peanut peel appeared to be the best route, producing cellulose nanocrystals with a high aspect ratio, 125, mean diameter of $4 \mathrm{~nm}$, and average length of 500 $\mathrm{nm}$, high stability in solution measured by the high potential value zeta, $-48.1 \pm 2.1 \mathrm{mV}$, thermal stability up to $200{ }^{\circ} \mathrm{C}$, CI of $75 \%$, and a yield of $3.25 \pm 0.02$ wt $\%$. The mercerization of peanut peel was crucial to the winning of individual nanometric fibers, which removes non-cellulosic components in the material. These values are comparable to values obtained for CNC produced from sources such as sisal and wood, demonstrating that it is an interesting alternative for the use of peanut peel and adds value to this residue, which could contribute to decreasing the discarding of waste and consequently mitigate environmental problems and develop new applications for this material.

\section{Authors' Contributions}

Conceptualization: Manrich, A.; Mattoso, L.H.C. Data acquisition: Manrich, A. Data analysis: Manrich,
A.; Martins, M.A. Design of methodology: Manrich, A.; Martins, M.A. Writing and editing: Manrich, A.; Martins, M.A.; Mattoso, L.H.C.

\section{Acknowledgments}

To the staff and facilities at Embrapa Instrumentation for supporting this study and Nanotechnology Network for Research in Agriculture - Rede AgroNano. This research was supported by the National System of the Nanotechnology Laboratories (SisNANO), a program from the Ministry of Science, Technology, Innovation and Communications (MCTIC), under contract no. 402287/2013-4.

\section{References}

Abraham, E.; Deepa, B.; Pothen, L.A.; Cintil, J.; Thomas, S.; John, M.J.; Anandjiwala, R.; Narine, S.S. 2013. Environmental friendly method for the extraction of coir fibre and isolation of nanofibre. Carbohydrate Polymers 92: 1477-1483.

Bano, S.; Negi, Y.S. 2017. Studies on cellulose nanocrystals isolated from groundnut shells. Carbohydrate Polymers 157: 1041-1049.

Bansode, R.R.; Randolph, P.; Hurley, S.; Ahmedna, M. 2012. Evaluation of hypolipidemic effects of peanut peel-derived polyphenols in rats on Western-diet. Food Chemistry 135: 1659-1666. 
Barcelo, J.M.; Gatchallan, A.M.; Aquino, I.J.B.; Ollero, D.R.E.; Cortez, F.L.D.; Costales, T.M.C.; Marzo, L.A.Q. 2015. FTIR Spectrum and antimutagenicity of Coffea arabica pulp and Arachis hypogaea testa in relation to their in vitro antioxidant properties. APJMR 3: 99-108.

Benitez, J.J.; Matas, A.J.; Heredia, A. 2004. Molecular characterization of the plant biopolyester cutin by AFM and spectroscopic techniques. Journal of Structural Biology 147: 179-184.

Cipriano, D.F.; Gonçalves, G.R.; Cunha, A.G.; Schettino Jr, M.A.; Chinelatto Jr., L.S.; Menezes, S.M.C.; Freitas, J.C.C. 2020. Application of solid state 13C NMR in the study of lignin and carbohydrate contents in acid-treated sugarcane bagasse samples. Revista Virtual de Química 12: 3 (in Portuguese, with abstract in English).

Constanza, K.E.; White, B.L.; Davis, J.P.; Sanders, T.H.; Dean, L.L. 2012. Value-added processing of peanut skins: antioxidant capacity, total phenolics, and procyanidin content of spraydried extracts. Journal of Agricultural Food Chemistry 60: $10776-10783$.

Fang, Z-F.; Liu, K-L.; Chen, F-S.; Zhang, L-F.; Guo, Z. 2014. Cationic surfactant-assisted microwave- $\mathrm{NaOH}$ pretreatment for enhancing enzymatic hydrolysis and fermentable sugar yield from peanut shells. Bioresources 9: 1290-1302.

Flauzino-Neto, W.P.; Silvério, H.A.; Dantas, N.O.; Pasquinia, D. 2013. Extraction and characterization of cellulose nanocrystals from agro-industrial residue - Soy hulls. Industrial Crops and Products 42: 480- 488.

Gupta, P.K.; Uniyal, V.; Naithani, S. 2013. Polymorphic transformation of cellulose I to cellulose II by alkali pretreatment and urea as an additive. Carbohydrate Polymers 94: 843-849.

Hames, B.; Scarlata, C.; Sluiter, A. 2008. Determination of Protein Content in Biomass/TP-510-42625. National Renewable Energy Laboratory, Golden, CO, USA.

Hathorn, C.S.; Sanders, T.H. 2012. Flavor and antioxidant capacity of peanut paste and peanut butter supplemented with peanut skins. Journal of Food Science 77: 407-411.

Husen, A.; Jawaid, M. 2020. Nanomaterials for agriculture and forestry applications. Elsevier, Amsterdam, Netherlands.

Iwamoto, S.; Lee, S-H.; Endo, T. 2014. The relationship between aspect ratio and suspension viscosity of wood cellulose nanofibers. Polymer Journal 46: 73-76.

Kalashnikova, I.; Bizot, H.; Cathala, B.; Capron, I. 2012. Modulation of cellulose nanocrystals amphiphilic properties to stabilize oil/water interface. Biomacromolecules 3: 267-275.

Kargarzadeh, H.; Ioelovich, M.; Ahmad, I.; Thomas, S.; Dufresne, A. 2017. Methods for extraction of nanocellulose from various sources. p. 1-51. In: Kargarzadeh, H.; Ahmad, I.; Thomas, S.; Dufresne, A., eds. Handbook of nanocellulose and cellulose nanocomposites. Wiley, Weinheim, Germany.

Karimi, K.; Taherzadeh, M.J. 2015. A critical review of analytical methods in pretreatment of lignocelluloses: composition, imaging, and crystallinity. Bioresource Technology 200: 10081018.

Klemm, D.; Heublein, B.; Fink, H.P.; Bohn, A. 2005. Cellulose: fascinating biopolymer and sustainable raw material. Angewandte Chemistry International Edition 44: 3358-3393.
Kouadri, I.; Satha, H. 2018. Extraction and characterization of cellulose and cellulose nanofibers from Citrullus colocynthis seeds. Industrial Crops and Products 124: 787-796.

Machado, C.M.; Benelli, P.; Tessaro, I.C. 2019. Constrained mixture design to optimize formulation and performance of foams based on cassava starch and peanut skin. Journal of Polymer and the Environment 27: 2224-2238.

Mariano, M.; Kissi, N.E.; Dufresne, A. 2018. Cellulose nanomaterials: size and surface influence on the thermal and rheological behavior. Polímeros 28: 93-102.

Modica, A.; Rosselli, S.; Catinella, G.; Sottile, F.; Catania, C.A.; Cavallaro, G.; Lazzara, G.; Botta, L.; Spinelli, A.; Bruno, M. 2020. Solid state 13C-NMR methodology for the cellulose composition studies of the shells of Prunus dulcis and their derived cellulosic materials. Carbohydrate Polymers 240: 116290 .

Morais, J.P.S.; Rosa, M.F.; Souza Filho, M.M.; Nascimento, L.D.; Nascimento, D.M.; Cassales, A.R. 2013. Extraction and characterization of nanocellulose structures from raw cotton Linter. Carbohydrate Polymers 91: 229- 235.

Nabinejad, O.; Sujan, D.; Rahman, M.E.; Davies, I.J. 2015. Effect of oil palm shell powder on the mechanical performance and thermal stability of polyester composites. Materials \& Design 65: 823-830.

National Peanut Board. Peanut Country. 2019. Available at: https://www.nationalpeanutboard.org/peanut-info/peanutcountry-usa.htm [Accessed Mar 15, 2020]

Nechyporchuk, O.; Belgacem, M.N.; Bras, J. 2016. Production of cellulose nanofibrils: a review of recent advances. Industrial Crops and Products 93: 2-25.

Nepomuceno, N.C.; Santos, A.S.; Oliveira, J.E.; Glenn, G.M.; Medeiros, E.S. 2017. Extraction and characterization of cellulose nanowhiskers from Mandacaru (Cereus jamacaru DC.) spines. Cellulose 24: 119-129.

Niu, F.G.; Li, M.Y.; Huang, Q.; Zhang, X.Z.; Pan, W.C.; Yang, J.S.; Li, J.R. 2017. The characteristic and dispersion stability of nanocellulose produced by mixed acid hydrolysis and ultrasonic assistance. Carbohydrate Polymers 165: 197-204.

Pandey, R.; Patel, S.; Pandit, P.; Shanmugam, N.; Jose, S. 2018. Colouration of textiles using roasted peanut skin- an agro processing residue. Journal of Cleaner Production 172: 13191326.

Park, S.; Baker, J.O.; Himmel, M.E.; Parilla, P.A.; Johnson, D.K. 2010. Cellulose crystallinity index: measurement techniques and their impact on interpreting cellulase performance. Biotechnology and Biofuels 3: 10.

Peng, B.L.; Dhar, N.; Liu, H.L.; Tam, K.C. 2011. Chemistry and applications of nanocrystalline cellulose and its derivatives: a nanotechnology perspective. Canadian Journal of Chemistry Engineering 89: 1191-1206.

Saxena, M.; Sarkar, S. 2012. Synthesis of carbogenic nanosphere from peanut skin. Diamond Related Materials 24: 11-14.

Silva, H.D.; Cerqueira, M.Â.; Vicente, A.A. 2012. Nanoemulsions for food applications: development and characterization. Food Bioprocess Technology 5: 854-867.

Smidt, E.; Schwanninger, M. 2005. Characterization of waste materials using FTIR Spectroscopy: process monitoring and quality assessment. Spectroscopy Letters 38: 247-270. 
Sobolev, V.S.; Cole, R.J. 2003. Note on utilisation of peanut seed testa. Journal of Science of Food and Agriculture 84: 105111.

Sofla, M.R.K.; Brown, R.J.; Tsuzuki, T.; Rainey, T.J. 2016. A comparison of cellulose nanocrystals and cellulose nanofibres extracted from bagasse using acid and ball milling methods. Advanced Natural Sciences: Nanoscience and Nanotechnology 7: $1-9$.

Song, K.; Zhu, X.; Zhu, W.; Li, X. 2019. Preparation and characterization of cellulose nanocrystal extracted from Calotropis procera biomass. Bioresources and Bioprocessing 6: 1-8.

Teixeira, E.M.; Corrêa, A.C.; Manzoli, A.; Leite, F.L.; Oliveira, C.R.; Mattoso, L.H.C. 2010. Cellulose nanofibers from white and naturally colored cotton fibers. Cellulose 17: 595-606.

Tonoli, G.H.D.; Teixeira, E.M.; Corrêa, A.C.; Marconcini, J.M.; Caixeta, L.A.; Pereira-da-Silva, M.A.; Mattoso, L.H.C. 2012. Cellulose micro/nanofibres from Eucalyptus kraft pulp: preparation and properties. Carbohydrate Polymers 89: 80-88.
Wang, B.; Sain, M.; Oksman, K. 2007. Study of structural morphology of hemp fiber from the micro to the nanoscale. Applied Composite Materials 14: 89-103.

Win, M.M.; Abdul-Hamid, A.; Baharin, B.S.; Anwar, F.; Saari, N. 2011. Effects of roasting on phenolics composition and antioxidant activity of peanut (Arachis hypogaea L.) kernel flour. European Food Research Technology 233: 599-608.

Xu, Z.; Du, P.; Meiser, P.; Jacob, C. 2012. Proanthocyanidins: oligomeric structures with unique biochemical properties and great therapeutic promise. Natural Products Communications 7: 381-388.

Yousefian, H.; Rodrigue, D. 2016. Effect of nanocrystalline cellulose on morphological, thermal, and mechanical properties of nylon 6 composites. Polymer Composites 37: 1473-1479.

Zhao, X.; Chen, J.; Du, F. 2012. Potential use of peanut byproducts in food processing: a review. Journal of Food Science Technology 49: 521-529. 